\title{
Special Issue of Applied Magnetic Resonance Celebrating the 85th Birthdays of Klaus Möbius and Kev M. Salikhov
}

\author{
Wolfgang Lubitz ${ }^{1} \cdot$ Anton Savitsky $^{2}$
}

Published online: 18 February 2022

(c) The Author(s) 2022

This special issue of Applied Magnetic Resonance (AMR) is dedicated to Klaus Möbius and Kev Salikhov who celebrated their 85th birthdays in 2021 (Fig. 1). A large number of colleagues and friends have contributed manuscripts to this issue honoring the two scientists. The manuscripts cover various aspects of magnetic resonance, spin chemistry and spin physics mirroring the impact of Klaus and Kev on these scientific fields. We, as guest editors, wish to thank all authors for their willingness and effort to submit an article on an exciting aspect of their work to this volume of AMR covering a large range of topics from quantum computing and single spin detection, via new spin exchange effects, on-chip EPR, high pressure EPR, EPR and ENDOR at very high fields, and photo-CIDEP/CIDNP, to new instrumental developments.

The editors have asked the two celebrated scientists to write an article about their professional and personal lives. It was not an easy task to convince them-but our invitation was finally successful. These two articles cover some little known aspects of Klaus' and Kev's lives in Germany and Russia - and are highly interesting to read.

Over the last 50 years, Klaus Möbius and Kev Salikhov have both made a large number of important contributions to the methodology, instrumentation, theory and application of magnetic resonance spectroscopy - and of EPR in particular. This has been honored by a large number of awards, prizes, orders and fellowships for both scientists, which are too numerous to be cited here and can be found in their CVs [1, 2]. It is quite remarkable that some of these honors are going far beyond their specialized field of work (e.g., the Lenin Prize, the Order of the Russian Federation and the State Prize of the Republic of Tatarstan to Kev, and the Max Planck Research Award of the Humboldt Foundation and the Cross of Merit of the Federal Republic

Wolfgang Lubitz

wolfgang.lubitz@cec.mpg.de

1 Max Planck Institute for Chemical Energy Conversion, Stiftstr. 34-36, 45470 Mülheim an der Ruhr, Germany

2 Faculty of Physics, Technical University Dortmund, Otto-Hahn-Str. 4a, 44227 Dortmund, Germany 


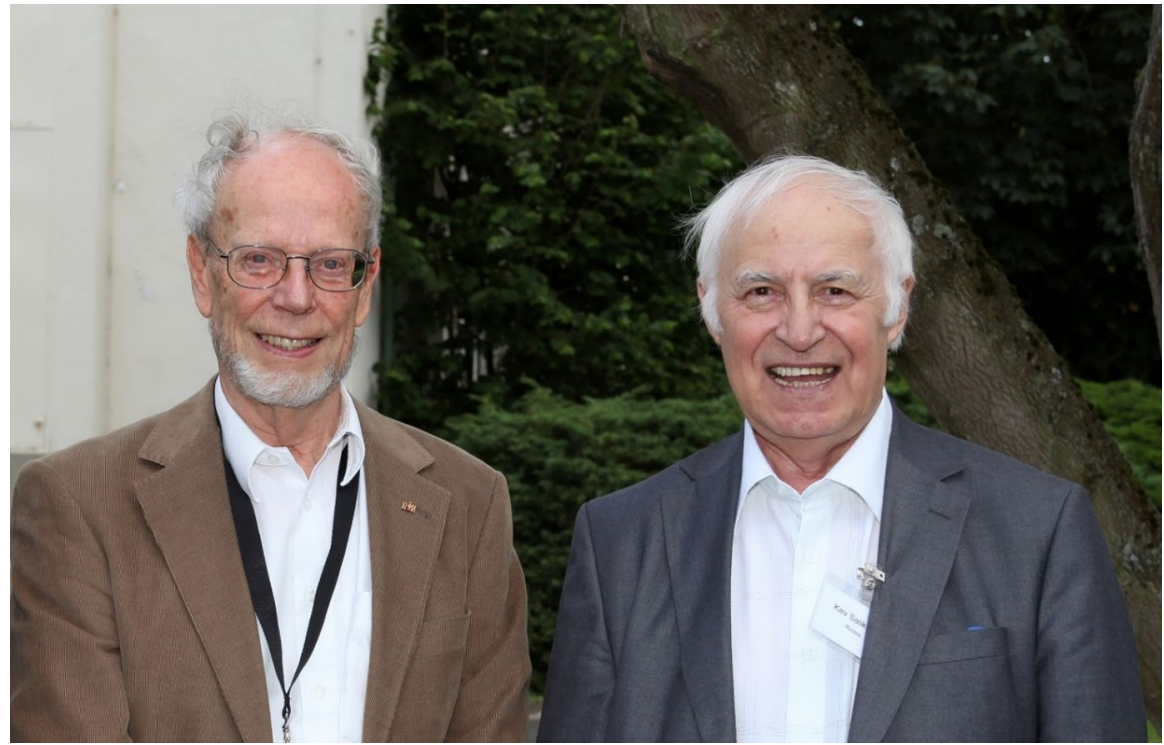

Fig. 1 Klaus Möbius (left) and Kev Salikhov (right). Mülheim an der Ruhr, July 2011

of Germany to Klaus) indicating the impact of their work on the field of science in general and on society.

In the following, we want to present a short personal view of the achievements of the two outstanding scientists.

\section{Klaus Möbius}

Klaus Möbius was born on 6 June 1936 in Berlin. He studied physics, mathematics and economy at the Freie Universität Berlin (FUB), where he also received his doctoral degree in 1965 in physics (supervised by Prof. R. Honerjäger) with a thesis on aromatic organic radicals studied by EPR and polarography, performed (in part) in an industrial (AEG) research laboratory in Berlin. After his habilitation in 1969 at the FUB Klaus spent a postdoctoral year with his family at UC Riverside in California in the group of August Maki where he became more familiar with electronnuclear double resonance (ENDOR) and learned about optically detected magnetic resonance (ODMR) spectroscopy. After his return to Berlin, he soon received a professor position in the Physics Department of the FU Berlin (1971). In the following years, he built up an impressive laboratory dedicated to various methods of magnetic resonance, to study organic and organometallic molecules in various matrices in their ground and excited states: distant ENDOR and NQR (with level-crossing) for $S=0$ states, local ENDOR and TRIPLE resonance for doublet ground states $(\mathrm{S}=1 / 2)$, and ODMR and related techniques for triplet excited states $(\mathrm{S}=1)$. Within one decade, the laboratory became one of the leading places for magnetic resonance not only in Germany but worldwide [3]. It is remarkable - and understandable - that Klaus, in spite of many opportunities, never left Berlin during his entire career. This 
was probably due to his dedication and love to the city and his private situationbut most of all owed to the unique working surrounding at the physics department of the FUB with much laboratory and office space, several staff and doctoral positions, access to very good students, truly excellent workshops with dedicated personnel, and colleagues and friends in the nearby chemistry department, who were prepared to synthesize compounds and supply samples for new projects, and last but not least due to sufficient funding by the university and the German Research Foundation (DFG), e.g., in the framework of several local Collaborative Research Centers (SFBs) and Priority Programs (SPPs) and other funding sources (e.g., the VW-Foundation).

In the early seventies, cw high-power ENDOR-in-solution has been developed in Klaus' lab (with his students R. Biehl and K.P. Dinse) by which many experiments became possible, in particular on (bio)organic radicals, with an enormous increase in spectral resolution compared to simple EPR [4, 5]. A milestone at this time certainly was the set-up of a cw ENDOR machine with a new resonator and mw/rf channel concept, which became the prototype for the first commercial cw-EPR/ ENDOR/TRIPLE spectrometer developed later by R. Biehl at Bruker. Novel features were in particular the electron-nuclear-nuclear triple resonance experiments (Special TRIPLE and General TRIPLE) realized in the lab by K.P. Dinse and R. Biehl, methods that are very helpful for assignment purposes, ENDOR signal enhancement and the determination of signs of the electron-nuclear hyperfine coupling constants (hfc's). In parallel, a theoretical understanding of the ENDOR/TRIPLE effect has been developed that allowed a prediction of the optimal experimental conditions for observation of practically all important magnetic nuclei in various types of organic and organometallic radicals and in different matrices or solvents [6]. This made cw-ENDOR/TRIPLE a versatile method for the investigation of radical species in a large variety of chemical and biological systems in liquid and frozen solutions [4]. From the extracted and assigned isotropic nuclear hfc's of the investigated species a map of the spin density distribution could be extracted and compared with quantum chemical calculations [7] delivering deep insight into the electronic structure. Highlights of Klaus' work during these years were certainly the applications of ENDOR/ TRIPLE to the radical cations and anions (and radical pairs) created by light in the photosynthetic reaction centers of bacteria and plants, and to related model systems, see e.g. $[8,9]$. This seminal work has substantially contributed to our understanding of light-induced charge separation and subsequent electron transfer and thus to the function of the reaction centers in photosynthesis [10].

A second path of early instrumental development in Klaus' lab (with coworker C. Winscom) concerned optical detection of magnetic resonance (ODMR) - which results in an enormous increase of sensitivity compared to the conventional microwave detection. This approach has led later to the detection of single spins in related experiments (by other groups). In the seventies and early eighties, the extension to optical detection of ENDOR (ODENDOR) and of nuclear quadrupole resonance (ODNQR) was also accomplished [3] and led to several important applications.

A very remarkable period in the field of magnetic resonance, based on earlier work of Yakov Lebedev's group in Moscow in the seventies [11], was the development of high field EPR, first in $\mathrm{cw}$ and later in pulse mode. In the mid-eighties 
Klaus Möbius' group in Berlin published a cw high field EPR spectrometer (at $95 \mathrm{GHz}$ ) that was later extended to pulsed work, including ESEEM/HYSCORE, DEER/PELDOR, ELDOR-detected NMR (EDNMR) and pulse ENDOR experiments; the instrument provided a large temperature range and also in situ light excitation [12]. An extension to $360 \mathrm{GHz}$ has also been demonstrated in Berlin in the mid-to-late nineties using a 14 Tesla magnet and quasi-optical microwave components, corrugated waveguides and Fabry-Perot resonators [13]. The history and instrumental development of high field/high frequency EPR is beautifully described in a monograph published by Möbius and Savitsky in 2009 [12], supplemented by two more recent reviews $[14,15]$ with various applications, in particular to biological systems. The further development and many new applications of HF EPR have been boosted by the DFG Priority Program "High-Field EPR in Biology, Chemistry and Physics" in Germany that was coordinated by Klaus Möbius from 1998 to 2004. In 1996, the first commercially available high-field EPR instrument constructed by Bruker BioSpin became available (Elexsys E600/E680, 94 GHz, 6 T magnet). This development was to a large extend based on the work in the laboratories of Klaus Möbius (FU Berlin) and Jan Schmidt (Leiden University) who further developed the earlier concept of Yakov Lebedev (Moscow) of high-field cw EPR into functional machines-including pulse EPR and ENDOR [12]. In more recent years, many groups in Europe and the world use HF-EPR. Commercial instrumentation at even higher frequencies/fields $(>95 \mathrm{GHz})$ is now available, following a trend that happened years before in NMR spectroscopy.

After his formal retirement at the FU Berlin (2001), Klaus Möbius continued his work at the Max Planck Society as permanent guest scientist of the Max Planck Institute for Bioinorganic Chemistry/Chemical Energy Conversion in Mülheim a. d. Ruhr in the Department of Biophysical Chemistry until 2017, where he cooperated with Wolfgang Lubitz and Anton Savitsky and his group, who studied (bio)chemical molecular systems using high field pulse EPR and ENDOR, see [12, 14, 15] and references therein. One of the central topics was an offspring of a collaboration with Giovanni Venturoli (University of Bologna) who is interested in the behavior of proteins embedded in and protected by specific sugar matrices, in particular trehalose. This sugar plays an important role in anhydrobiosis ("life without water"), e.g., in desert environments (in "resurrection plants" and some microorganisms). The combined approach of fast optical and FTIR spectroscopy and high-field EPR techniques led to a model for the protecting effect of the sugar matrix on the investigated protein with implications for photosynthesis in arid and hot environments [16].

All his scientific life Klaus had a keen interest in molecules with unusual physical and electronic structure and chemical behavior. As a young scientist, he studied a series of large $\pi$-aromatic molecules. No wonder that at the end of his career he turned back to his beginnings and studied the problem of Hückel/Möbius topology switches in extended $\pi$-aromatic systems and published two papers in this field using EPR/ENDOR — supplemented by DFT calculations-on selected (paramagnetic) systems synthesized by the group of Latos-Grazynsky in Wroclaw (Poland). He also recognized that there is much more behind the story and wrote a monograph on this problem "The Möbius Strip Topology" together with M. Plato and A. Savitsky to 
be published in 2022 [17]. The book is also covering many topics beyond the basic scientific aspects, e.g., examples from materials science, the arts and architecture.

Starting from the late seventies/early eighties Klaus has become interested (via contact with Arnold Hoff, Leiden) in biological problems, in particular related to photosynthesis, the central energy conversion process on earth. Its understanding on a molecular level-in particular the primary processes of light capture, excitation transfer, charge separation, electron transport and finally the storage of the sun's energy in molecular compounds-is of utmost important for solving the energy problem on our planet, and thus indispensable for our society and our personal lives. His fascination of the research in photosynthesis and the people behind it led him - together with his friend and colleague Giovanni Giacometti from Padua University - to write a book (a play based on dialogues) called "Life on Earth Through Photosynthesis" [18] that appeared in print in 2016. It covers many interesting aspects of the history of photosynthesis and related scientific insights from the eighteenth century till today in a format different from that usually used to communicate scientific results and knowledge and is thus very worth reading.

\section{Kev Minullinovich Salikhov}

Kev Salikhov was born on 3 November 1936 in a small village close to the Ural Mountains (Krasnaya Rechka, Soviet Autonomous Republic of Bashkortostan) as the second youngest child of a large Tatar family. During his school time, his teachers and family quickly recognized that he was a very gifted child. He finished high school in his home district and then went to Kazan (Soviet Autonomous Republic of Tatarstan), where he graduated in 1959 from the State University, Department of Physics and Mathematics (supervisor Prof. S. Altschuler). For his PhD, he moved to Leningrad (now St. Petersburg) at the Institute of Macromolecular Sciences of the Russian Academy of Sciences (RAS), where he received his doctoral degree in 1962 with a topic on theoretical polymer physics, supervised by Profs. M. Volkenstein and Yu. Gotlib. Afterwards, he accepted a position as research scientist in Novosibirsk (Akademgorodok) at the famous Institute for Chemical Kinetics and Combustion founded by Prof. V. V. Voevodsky. In 1963, he moved there with his wife Zoya and founded a family. In the institute Kev found excellent conditions to establish his own theoretical research field in chemical physics, supported by collaborations with various experimental groups.

During his time in Akademgorodok, Kev Salikhov pioneered several fields of research. For Heisenberg exchange, he developed a general theory describing spin exchange in encounters of free radicals, triplet state molecules and paramagnetic ions [19] — several of the described phenomena were only confirmed decades later experimentally. His work also laid the foundation of "Spin Chemistry", a new research field dealing with the role of the spin as well as the effect of magnetic fields and magnetic isotopes on chemical reactions [20,21] and the chemically induced polarization of nuclear and electron spins (CIDNP, CIDEP) to which Kev contributed substantially. In 1991, a conference on Spin Chemistry was established followed by up to now 15 biannual meetings that demonstrate the large interest of scientists around the world in this steadily growing research field. 
Kev Salikhov also contributed greatly to the development of pulse EPR in Akademgorodok. He theoretically predicted the phenomenon of spin echo modulation (ESEEM technique) described by Rowan, Hahn and Mims in 1965 for single crystals, to also exist in disordered solids and frozen solutions [22], which has been of great importance for many applications. He also proposed the role of selective excitation of a spin system by mw pulses forming the spin echo and developed the theory of phase relaxation due to dipolar spin-spin interactions. His monograph "Electron Spin Echo and Its Application" published in 1976 [23] was the first covering the topic of pulse EPR. Together with colleagues in Novosibirsk, he proposed in 1981 the PELDOR (or DEER) technique [24] that has now-40 years laterbecome one of the most valuable and widely used EPR methods; it is employed for the determination of (spin) distances and structure determinations in general, e.g., in specifically (selectively) spin-labeled macromolecules like proteins.

In 1988, Kev Salikhov was offered the position as director of the Zavoisky Physical Technical Institute of the RAS in Kazan (Tatarstan) that he accepted with pleasure since—as he said—“Kazan is the Motherland of EPR spectroscopy". Here Kev continued his great work that he had started in Novosibirsk. For example, he predicted unusual effects in the fast light-induced processes in photosynthetic systems (RCs) that lead to quantum beats and anomalous phase behavior of the transient EPR spectra observed in spin correlated radical pairs. These effects were observed experimentally and advantageously used to determine distances and relative orientations in highly complex charge separated systems, see e.g. [25]. Furthermore, he introduced (with D. Stehlik) the concept of the observer spin (3-spin system) in structure determination [26] and developed protocols for quantum teleportation across a biological membrane [27], which was finally realized experimentally more than a decade later on a photo-induced electron donor-acceptor system [28]. Salikhov also contributed to EPR imaging, especially covering conducting and lossy dielectric materials [29, 30]. Early in the new millennium, Kev got interested in quantum computing and informatics and suggested protocols to use electron spins as qubits together with his student M. Volkov [31]. In addition, his interest in spin exchange has been ongoing until today, a field where he continues to contribute important ideas and recently published a book introducing a paradigm shift in the understanding of spin exchange and its manifestations in EPR spectroscopy [32].

Within a decade after taking over the position in Kazan, Kev made the Zavoisky Institute a center of excellence of EPR spectroscopy. However, his success in Kazan was not only based on his scientific achievements but also due to his truly remarkable talent to act as a powerful director and administrator. He introduced new techniques in the institute-also beyond magnetic resonance-and formed the Department of Chemical Physics with well-equipped laboratories dedicated to various modern scientific fields, from advanced EPR and spin chemistry via ultrafast optical spectroscopy to quantum computing. In 1989, the Chair of Chemical Physics was founded at the Kazan State University (now Federal University) on his initiative. Furthermore, he has been a major player in establishing the Academy of Sciences of the Republic Tatarstan in 1991 for which he served as vice president for many years. His remarkable engagement for Kazan and Tatarstan was honored by several prizes and orders from the state and city (see his CV in [1]). Since 1997, he has 
been corresponding member and since 2011 full member of the Russian Academy of Sciences.

Already in $1990 \mathrm{Kev}$ founded the journal Applied Magnetic Resonance published by Springer Verlag, which is now existing more than 30 years with him as editor-inchief. For a long time, it has been the only journal in Russia publishing only in English and read by a much wider community than the Russian journals. This opened Russian Magnetic Resonance to the "world"-an important step for EPR, NMR and related communities. Shortly after his arrival in Kazan Kev also established the Zavoisky Award, given every year to an outstanding scientist from EPR or related fields. In connection with the annual award ceremony in Kazan, an international conference series has been established by him; until this day Kev is still involved in the organization of these meetings.

Kev Salikhov disseminated his scientific ideas and findings not only in many invited lectures at conferences, symposia and seminars around the world but also in about 250 original publications and a large number of monographs. He has been active in teaching for more than 50 years and wrote several books dedicated specifically to his work with students. Kev has also supervised a significant number of $\sim 25$ $\mathrm{PhD}$ students. It is quite remarkable that at the age of 85 , he is still actively giving courses, e.g., on Quantum Computing (in English) at the Innopolis University close to Kazan. It is quite obvious that the work and exchange with young people remain to be very important for him.

For both, Klaus and Kev, it has been important to collaborate with other scientists-beyond borders. This has been especially true for Germany and Russia and important for the scientific relationship between the two countries. It started with meetings at conferences and continued with mutual lab visits in Berlin and several institutions and universities in Russia, with student exchange, and with a growing collaboration between the laboratories of Klaus and Kev. A memorable journey to Russia by a German delegation of scientists (K. Möbius, M. Plato, W. Lubitz, H. Kurreck, D. Stehlik, H.-M. Vieth, P. Jaegermann, J. Schlüpmann, O. Burghaus) organized by Klaus Möbius in autumn 1989 just before the fall of the iron curtain has paved the way-with visits of Moscow, Leningrad, Akademgorodok/Novosibirsk and Kazan. These personal contacts built the foundation for long standing and fruitful cooperations with Russian scientists - also with Kev Salikhov who was just on the move from Novosibirsk to Kazan in 1989.

As Kev and Klaus always said: "Friendship and mutual understanding cannot be overemphasized as basis for (and outcome of) scientific collaborations"- this is often of equal importance as the scientific results obtained and is of particular importance for people from different nations. In this context, it should be emphasized that collaborations should never be a one-way street-and this has indeed never been the case between Russian and German EPR groups. Although much modern instrumental developments and great applications were done in the West, it is also clear that EPR has been invented in Russia, the first EPR high field instrumentation and several pulse EPR techniques as well as the theoretical foundation of 
many effects observed in spin physics andspin resonance were developed by Russian scientists.

Dear Klaus, dear Kev: we congratulate you to your 85th birthdays and wish you continuing pleasure, satisfaction and success in your ongoing scientific work, good health and the right spirit to master the many problems of old age. Thank you for your dedication to magnetic resonance and EPR in particular, to which you have contributed so much! The magnetic resonance community would be much poorer without your insights and your experimental and theoretical developments over the years, which have opened vistas to new and exciting applications for many scientists from Physics, Chemistry, and the Life Sciences. Last but not least, we would also like to thank you for your great support and lasting friendship over so many years. It was, therefore, a pleasure for us to act as editors for this special issue honoring your life achievements and celebrating your 85th birthdays with you.

The Guest Editors.

Wolfgang Lubitz and Anton Savitsky.

Funding Open Access funding enabled and organized by Projekt DEAL.

Open Access This article is licensed under a Creative Commons Attribution 4.0 International License, which permits use, sharing, adaptation, distribution and reproduction in any medium or format, as long as you give appropriate credit to the original author(s) and the source, provide a link to the Creative Commons licence, and indicate if changes were made. The images or other third party material in this article are included in the article's Creative Commons licence, unless indicated otherwise in a credit line to the material. If material is not included in the article's Creative Commons licence and your intended use is not permitted by statutory regulation or exceeds the permitted use, you will need to obtain permission directly from the copyright holder. To view a copy of this licence, visit http://creativecommons.org/licen ses/by/4.0/.

\section{References}

1. Z. Phys, Chem. 231, 147-166 (2017)

2. https://www.physik.fu-berlin.de/en/einrichtungen/alte_ags/ag-moebius/cv/index.html

3. K. Möbius, W. Fröhling, F. Lendzian, W. Lubitz, M. Plato, C.J. Winscom, J. Phys. Chem. 86, 44914507 (1982)

4. H. Kurreck, B. Kirste, W. Lubitz, Electron nuclear double resonance spectroscopy of radicals in solution (VCH Publishers, New York, 1988)

5. K. Möbius, M. Plato, W. Lubitz, Phys. Rep. 87, 171-208 (1982)

6. M. Plato, W. Lubitz, K. Möbius, J. Phys. Chem. 85, 1202-1219 (1981)

7. M. Plato, K. Möbius, W. Lubitz, Molecular orbital calculations on chlorophyll radical ions, in Chlorophylls. ed. by H. Scheer (CRC Press, Boca Raton, Florida, 1991), pp. 1015-1046

8. F. Lendzian, W. Lubitz, H. Scheer, C. Bubenzer, K. Möbius, J. Am. Chem. Soc. 103, 4635-4637 (1981)

9. F. Lendzian, M. Huber, R.A. Isaacson, B. Endeward, M. Plato, B. Bönigk, K. Möbius, W. Lubitz, G. Feher, Biochim. Biophys. Acta. 1183, 139-160 (1993)

10. M. Plato, K. Möbius, M.E. Michel-Beyerle, M. Bixon, J. Jortner, J. Am. Chem. Soc. 110, 72797285 (1988) 
11. A.I. Kokorin, K. Möbius, O.G. Poluektov, Appl. Magn. Reson. 51, 769-771 (2020)

12. K. Möbius, A. Savitsky, High-field EPR spectroscopy on proteins and their model systems: characterization of transient paramagnetic states (RSC Publishing, London, 2009)

13. M.R. Fuchs, T.F. Prisner, K. Möbius, Rev. Sci. Instr. 70, 3681-3683 (1999)

14. K. Möbius, W. Lubitz, A. Savitsky, Prog. Nucl. Magn. Reson. Spectrosc. 75, 1-49 (2013)

15. K. Möbius, W. Lubitz, N. Cox, A. Savitsky, Magnetochem. 4, 50 (2018)

16. K. Möbius, A. Savitsky, A. Nalepa, M. Malferrari, F. Francia, W. Lubitz, G. Venturoli, Appl. Magn. Reson. 46, 435-464 (2015)

17. K. Möbius, M. Plato, A. Savitsky, The Möbius strip topology: history, science and applications in nanotechnology, materials, and the arts (Jenny Stanford Publishing, Singapore, 2022)

18. K. Möbius, G. Giacometti, Life on earth through photosynthesis (Bononia Univ Press, 2016)

19. Y.N. Molin, K.M. Salikhov, K.I. Zamaraev, Spin exchange. Principles and applications in chemistry and biology (Springer, Berlin, 1980)

20. K.M. Salikhov, R.Z. Sagdeev, A.L. Buchachenko, Spin polarization and magnetic effects in radical reactions (Elsevier, Netherlands, 1984)

21. K.M. Salikhov, Magnetic isotope effect in radical reactions: an introduction (Springer Vienna, 1996)

22. G.M. Zhidomirov, K.M. Salikhov, Theor. Exper. Chem. 4, 332-334 (1971)

23. K.M. Salikhov, A.G. Semenov, Y.D. Tsvetkov, Electron spin echo and its application (Nauka, Novosibirsk, 1976)

24. A. Milov, K. Salikhov, M. Shirov, Solid State Phys. (Russian). 23, 975-982 (1981)

25. R. Bittl, S.G. Zech, J. Phys. Chem. B. 101, 1429-1436 (1997)

26. K.M. Salikhov, A.J. van der Est, D. Stehlik, Appl. Magn. Reson. 16, 101-134 (1999)

27. K.M. Salikhov, J.H. Golbeck, D. Stehlik, Appl. Magn. Reson. 31, 237-252 (2007)

28. B.K. Rugg, M.D. Krzyaniak, B.T. Phelan, M.A. Ratner, R.M. Young, M.R. Wasielewski, Nat. Chem. 11, 981-986 (2019)

29. L.K. Aminov, M.P. Tseitlin, K.M. Salikhov, Appl. Magn. Reson. 16, 341-362 (1999)

30. M. Tseitlin, K. Aminov, K. Salikhov, Appl. Magn. Reson. 16, 325-340 (1999)

31. M.Y. Volkov, K.M. Salikhov, Appl. Magn. Reson. 41, 145-154 (2011)

32. K.M. Salikhov, Fundamentals of spin exchange: story of a paradigm shift (Springer, Cham, 2019)

Publisher's Note Springer Nature remains neutral with regard to jurisdictional claims in published maps and institutional affiliations. 